\title{
Increased Expression of Brain-Derived Neurotrophic Factor Induces Formation of Basal Dendrites and Axonal Branching in Dentate Granule Cells in Hippocampal Explant Cultures
}

\author{
Steve C. Danzer, ${ }^{1}$ Kristy R. C. Crooks, ${ }^{2}$ Donald C. Lo, ${ }^{2}$ and James O. McNamara ${ }^{1,2,3,4}$ \\ Departments of ${ }^{1}$ Medicine (Neurology), ${ }^{2}$ Neurobiology, ${ }^{3}$ Pharmacology, and ${ }^{4}$ Molecular Cancer Biology, Duke University \\ Medical Center, Durham, North Carolina 27710
}

During limbic epileptogenesis in vivo the dentate granule cells (DGCs) exhibit increased expression of brain-derived neurotrophic factor (BDNF), followed by striking morphologic plasticities, namely the formation of basal dendrites and the sprouting of mossy fibers. We hypothesized that increased expression of BDNF intrinsic to DGCs is sufficient to induce these plasticities. To test this hypothesis, we transfected DGCs in rat hippocampal slice cultures with BDNF or nerve growth factor (NGF) via particle-mediated gene transfer, and we visualized the neuronal processes with cotransfected green fluorescent protein. Trans-

Elucidating the mechanisms of limbic epileptogenesis in cellular and molecular terms may provide novel therapeutic approaches for epilepsy prevention. The discovery that neurotrophin mRNA content is increased during epileptogenesis (Gall and Isackson, 1989) led to the idea that neurotrophic factors may contribute to the lasting structural and functional modifications underlying epilepsy (Gall, 1993).

Among the diverse neurotrophic factors exhibiting increased expression during epileptogenesis, brain-derived neurotrophic factor (BDNF) in particular is implicated as playing a causal role. Specifically, both pharmacological (Binder et al., 1999a) and genetic (Kokaia et al., 1995; Lahteinen et al., 2002) manipulations designed to reduce BDNF expression and/or activation of its receptor, TrkB, delay epileptogenesis. Moreover, transgenic mice overexpressing BDNF exhibit an enhanced response to epileptogenic stimuli (Croll et al., 1999). Together, these results are consistent with the idea that enhanced activation of TrkB by BDNF promotes epileptogenesis.

One population of neurons in which enhanced activation of TrkB may promote epileptogenesis is the dentate granule cells (DGCs) of the hippocampus. Striking increases of BDNF expression have been identified in DGCs in experimental models and humans with epilepsy (Wetmore et al., 1994; Mathern et al., 1997;

\footnotetext{
Received May 21, 2002; revised Aug. 28, 2002; accepted Sept. 3, 2002.

This work was supported by National Institutes of Health (NIH) Grants NS07370 and NS32334 and National Institute of Neurological Disorders and Stroke Grant NS17771. S.C.D. was supported by an NIH National Research Service Award grant and the Pharmaceutical Research and Manufacturers of America Foundation. We also thank Dr. David Fitzpatrick for the use of his Neurolucida system and Dr. Ram Puranam, Dr. Victor Nadler, and Keri Kaeding for useful comments on previous versions of this manuscript. We offer special thanks to Charles Hemphill of Leica Microsystems for assistance in collecting confocal images.

Correspondence should be addressed to Dr. James O. McNamara, Duke University Medical Center, 401 Bryan Research Building, Durham, NC 27705. E-mail: jmc@neuro.duke.edu.

Copyright (C) 2002 Society for Neuroscience $\quad 0270-6474 / 02 / 229754-10 \$ 15.00 / 0$
}

fection with BDNF produced significant increases in axonal branch and basal dendrite number relative to NGF or empty vector controls. Structural changes were prevented by the tyrosine kinase inhibitor K252a. Thus increased expression of BDNF within DGCs is sufficient to induce these morphological plasticities, which may represent one mechanism by which BDNF promotes limbic epileptogenesis.

Key words: dentate granule cell; basal dendrite; mossy fiber sprouting; BDNF; epileptogenesis; biolistics
Yan et al., 1997; Takahashi et al., 1999; Murray et al., 2000). Importantly, increased activation of TrkB receptors in the distribution of DGC axons has been identified in animal models of epileptogenesis (Binder et al., 1999b; He and McNamara, 2002).

Increased TrkB activation in the distribution of DGC axons is of particular interest because these neurons normally serve as a barrier to invasion of hippocampal circuitry by seizure activity (Collins et al., 1983). Importantly, the "barrier function" of granule cells is compromised in epileptic animals (Behr et al., 1998). Compromise of the barrier may be mediated in part by increased recurrent excitatory synapses formed among DGCs in the epileptic condition (Wuarin and Dudek, 1996; Molnar and Nadler, 1999; Okazaki et al., 1999; Lynch and Sutula, 2000; Wuarin and Dudek, 2001). Two distinct morphological plasticities identified in DGCs of the epileptic brain have been proposed to underlie recurrent excitatory synapses among these neurons. One is the sprouting of DGC axons (Nadler et al., 1980; Tauck and Nadler, 1985; Sutula et al., 1989; Babb et al., 1991, which leads to the formation of recurrent excitatory synapses on apical dendrites of granule cells (Frotscher and Zimmer, 1983; Franck et al., 1995; Okazaki et al., 1995; Wenzel et al., 2000). Another is the recently discovered formation of basilar dendrites identified in DGCs in experimental models (Spigelman et al., 1998). By projecting into the hilus, basal dendrites of granule cells become targets for innervation by the rich network of granule cell axons in this region.

Because BDNF and TrkB exert powerful morphoregulatory effects on diverse types of neurons (Horch et al., 1999; Yacoubian and Lo, 2000; Patapoutian and Reichardt, 2001) and because increased expression of BDNF and increased activation of TrkB occur in the mossy fiber pathway of the DGCs during limbic epileptogenesis, we hypothesized that increased expression of BDNF in granule cells is sufficient to induce some of the morphologic plasticities identified in granule cells in limbic epilepsy. 


\section{MATERIALS AND METHODS}

Organotypic hippocampal explant method. Slice cultures were prepared from 10-d-old (P10) male Sprague Dawley rat pups from multiple mothers (Zivic-Miller, Zelienople, PA) and then maintained via the interface method (Stoppini et al., 1991). All procedures conformed to National Institutes of Health and Institutional guidelines for the care and use of animals. After treatment with ketamine $(100 \mathrm{mg} / \mathrm{kg}$, i.p.) the animals were decapitated, brains were bisected in the sagittal plane, and blocks containing the hippocampus and cortex were removed. Slices $(400 \mu \mathrm{m}$ each) were isolated with a McIlwain tissue chopper and plated onto Millicel inserts (Millipore, Bedford, MA) in six-well plates with $1.2 \mathrm{ml}$ of medium $(50 \%$ minimum essential medium, 25\% HBSS, $25 \%$ heatinactivated horse serum, $10 \mathrm{~mm}$ HEPES, $0.5 \%$ GlutaMaxII (all from Invitrogen, San Diego, CA), and $0.65 \%$ glucose (Sigma, St. Louis, MO), $\mathrm{pH} 7.2$, preheated to $37^{\circ} \mathrm{C}$. The slices were incubated at $37^{\circ} \mathrm{C}$ in a $95 \%$ $\mathrm{CO}_{2} / 5 \% \mathrm{O}_{2}$ air mix. For K252a experiments the tissue culture inserts were transferred to new six-well plates with medium containing either 200 nm K252a (Calbiochem, La Jolla, CA) or $1 \mu$ l of DMSO (Sigma) per milliliter of medium, reflecting the final concentration of DMSO resulting from the dilution of K252a stock solution.

Construction and characterization of pro-BDNF/NGF-HA and BDNF$H A$. Four plasmids were used in these experiments, BDNF-HA (henceforth referred to as $\mathrm{BDNF}$ ), pro-BDNF/NGF-HA (henceforth referred to as nerve growth factor, NGF), pEGFP-IRESneo (henceforth referred to as green fluorescent protein, GFP), and pcDNA3 (Invitrogen). The pcDNA3 plasmid lacked an insert and was used as a negative control. The pEGFP-IRESneo plasmid (generous gift of Dr. Nancy Ip, Hong Kong University of Science and Technology) expresses enhanced GFP (EGFP) driven by a CMV promoter in the pIRESneo plasmid (Clontech, Palo Alto, CA). The BDNF plasmid contains the full-length rat BDNF sequence (nucleotides 2123-2842, accession number D10938; National Center for Biotechnology database, Bethesda, MD), followed by a single $\mathrm{C}$-terminal hemagglutinin (HA) tag in a pcDNA3 vector with a CMV promoter. The NGF plasmid contains the rat pro-BDNF sequence (nucleotides 2123-2519, accession number D10938; National Center for Biotechnology database), followed by the mouse NGF precursor sequence (nucleotides 519-836, accession number S62089) with a single $\mathrm{C}$-terminal $\mathrm{HA}$ tag in a pcDNA3 vector. Both NGF and BDNF plasmids have consensus Kozak initiation sites. Endogenous BDNF and NGF are expressed in pro-forms that then are cleaved into active BDNF or NGF. The substitution of the pro-BDNF sequence for the pro-NGF sequence does not change the structure of the released NGF protein, but it does change the expression pattern of the NGF protein as assessed by epitope tag immunohistochemistry. Inclusion of the pro-NGF sequence resulted in low levels of NGF in the soma, whereas expression of the pro-BDNF/NGF plasmid resulted in high levels of NGF in the soma (data not shown). Because this latter expression pattern was similar to the expression of transfected BDNF, the pro-NGF/BDNF plasmid served as a better control. BDNF and NGF plasmids were generously provided by Richard Murphy and Stephen Morris (Montreal Neurological Institute, Quebec, Canada).

Particle-mediated gene transfer. Hippocampal slices were transfected by using a particle-mediated gene transfer device according to the manufacturer's protocols (Helios, Bio-Rad, Hercules, CA) 1-4 hr after slice preparation. Briefly, either 16 or $25 \mathrm{mg}$ of $1.6 \mu \mathrm{m}$ gold particles (BioRad) was coated with the following plasmid combinations: $0.25 \mu \mathrm{g}$ of GFP/mg gold, $0.25 \mu \mathrm{g}$ of GFP plus $1.75 \mu \mathrm{g}$ of empty PCDNA-3 plas$\mathrm{mid} / \mathrm{mg}$ gold, $0.25 \mu \mathrm{g}$ of GFP plus $1.75 \mu \mathrm{g}$ of NGF $/ \mathrm{mg}$ gold, and $0.25 \mu \mathrm{g}$ of GFP plus $1.75 \mu \mathrm{g}$ of BDNF/mg gold. Tissue cultures were transfected in six-well plates at 300 psi. Nylon mesh (90 $\mu \mathrm{m}$ thread spacing) was placed between the barrel of the gene gun and the culture during transfection. At $24 \mathrm{hr}$ after transfection the cultures were fixed for $1.5 \mathrm{hr}$ in $2.5 \%$ paraformaldehyde and $4 \%$ sucrose. Then the cultures were cryoprotected overnight in $30 \%$ sucrose in PBS, frozen on dry ice, and stored at $-80^{\circ} \mathrm{C}$.

Immunohistochemistry. Frozen cultures were thawed in PBS and blocked for $3 \mathrm{hr}$ in 10\% normal goat serum (Invitrogen), 2\% BSA (Sigma), and $0.5 \%$ Igepal (Sigma) in PBS. All slices (including those transfected with GFP only) were incubated overnight in $5 \mu \mathrm{g} / \mathrm{ml}$ rabbit polyclonal anti-GFP protein antibody (Chemicon, Temecula, CA) and $500 \mathrm{ng} / \mathrm{ml}$ rat monoclonal anti-HA peptide antibody (Roche, Mannheim, Germany). Secondary antibodies included 1:400 Oregon green 488 goat anti-rabbit $(2 \mathrm{mg} / \mathrm{ml}$ stock; Molecular Probes, Eugene, OR) and 1:500 Alexa Fluor 594 goat anti-rat ( $2 \mathrm{mg} / \mathrm{ml}$ stock; Molecular Probes). Slices were rinsed in PBS, mounted to Superfrost Plus slides (Port City Diag- nostics, Wilmington, NC), dehydrated, cleared in xylenes, and coverslipped with Krystalon (EM Science, Gibbstown, NJ).

Neuron selection. Small numbers of principal neurons (usually 0-4) were transfected in each culture, making it easy to distinguish the processes of individual neurons. Anatomical criteria were used to identify a neuron as a DGC, CA3 or CA1 pyramidal cell, or interneuron, respectively. For DGCs (1) the soma was located in either the superior blade or crest of the DGC layer or adjacent hilus or molecular layer (within $100 \mu \mathrm{m}$ ), and (2) the dendritic tree exhibited a fan-like spread in the molecular layer of the dentate gyrus and/or an axon in stratum lucidum of CA3. For CA3 pyramidal cells (1) the cell body was located in the CA3 pyramidal cell layer, (2) the apical and basal dendritic fields were as described by Ramon y Cajal (1893) and Lorente de No (1934), and (3) the cell displayed a large soma and lack of collateral branches on the proximal apical dendrite relative to CA1 pyramidal cells. CA2 pyramidal cells were grouped with CA3 pyramidal cells. For CA1 pyramidal cells (1) the soma was located in the CA1 pyramidal cell layer, (2) apical and basal dendritic fields typical of a pyramidal cell were present (Ramon y Cajal, 1893; Lorente de No, 1934), and (3) the soma was smaller than CA3 pyramidal cells and collaterals off the proximal apical dendrite were present. In addition to these criteria, those neurons that were selected for analysis had to be filled completely with GFP in the case of DGCs or at least filled out to the more distal regions of the dendrites in the case of pyramidal cells. Furthermore, neurons had to be absent of degenerative changes (e.g., dendritic blebbing). Finally, to verify expression of the cDNA that was being studied, neurons transfected with either BDNF or NGF must have exhibited immunoreactivity for the HA tag. Importantly, neuron selection and analysis were conducted with the experimenter blind to the treatment group.

Neuronal imaging and analysis. Neurons selected for analysis were imaged with a Bio-Rad MRC 600 confocal microscope and a Nikon Fluor $40 \times$ oil objective. Endogenous autofluorescence of the tissue provides a Nissl-like stain, making it possible to distinguish hippocampal subfields. Neurons were $z$-sectioned at $0.5 \mu \mathrm{m}$ increments, using Kalman filtering and the COMOS software of Bio-Rad (version 7.1). Image stacks were collapsed to make two-dimensional reconstructions of the neurons. Images then were imported into Photoshop, the brightness and contrast were optimized, and montages were made if necessary. Photoshop images were imported into the Neurolucida software program (MicroBrightField, Colchester, VT; version 4.10d), and computerized twodimensional reconstructions of the neurons were made.

To be counted, axonal branches and apical or basal dendrites had to be at least $10 \mu \mathrm{m}$ in length. Basal dendrites were counted as those dendrites that originated from the hilar side of the soma, even if the dendrite subsequently curved back into the dentate molecular layer. Transverse spread of the apical dendritic field (Claiborne et al., 1990) and the depth into the molecular layer reached by the longest dendrite also were determined from confocal reconstructions. Axonal branch number and location of the soma within the granule cell layer were determined directly from the tissue slices via the Neurolucida system and a Zeiss Axioskop (Oberkochen, Germany) microscope equipped with a motorized stage and a Zeiss Fluor $40 \times$ oil objective.

The medial-to-lateral location of each DGC was determined by measuring the distance between the soma and the tip of the superior blade of the DGC layer; distance from the hilus was determined by measuring the distance between the soma and the hilar/granule cell layer border. Neuronal parameters were collected with the accompanying Neuroexplorer software (MicroBrightField, version 3.25).

Primary dendrite number was determined by fluorescent microscopy on a Zeiss Axiovert 135 microscope equipped with Zeiss Achroplan $20 \times$ [numerical aperture (NA), 0.45] and Zeiss Fluor 40× oil (NA, 1.30) objectives. This system also was used to determine the number of giant mossy fiber boutons. For each DGC the furthest subfield of the mossy fiber pathway reached by the longest axon collateral was determined also; the subfields included the DGC layer, hilus, CA3c, CA3b, and CA3a. Scores of 1, 2, 3, 4, or 5, respectively, were assigned. Fully developed mossy fibers will reach CA3a, whereas less developed fibers will terminate in one of the preceding subfields.

To assess BDNF and NGF expression levels, we captured images of transfected neurons immunostained for HA by a digital camera (Princeton Instruments, Trenton, NJ). Exposure settings were identical for each image. The MetaMorph Imaging program (Universal Imaging, West Chester, PA) then was used to obtain an average gray value over the soma of the transfected neuron minus the background gray value.

Statistical significance was determined by using SigmaStat, version 2.0 


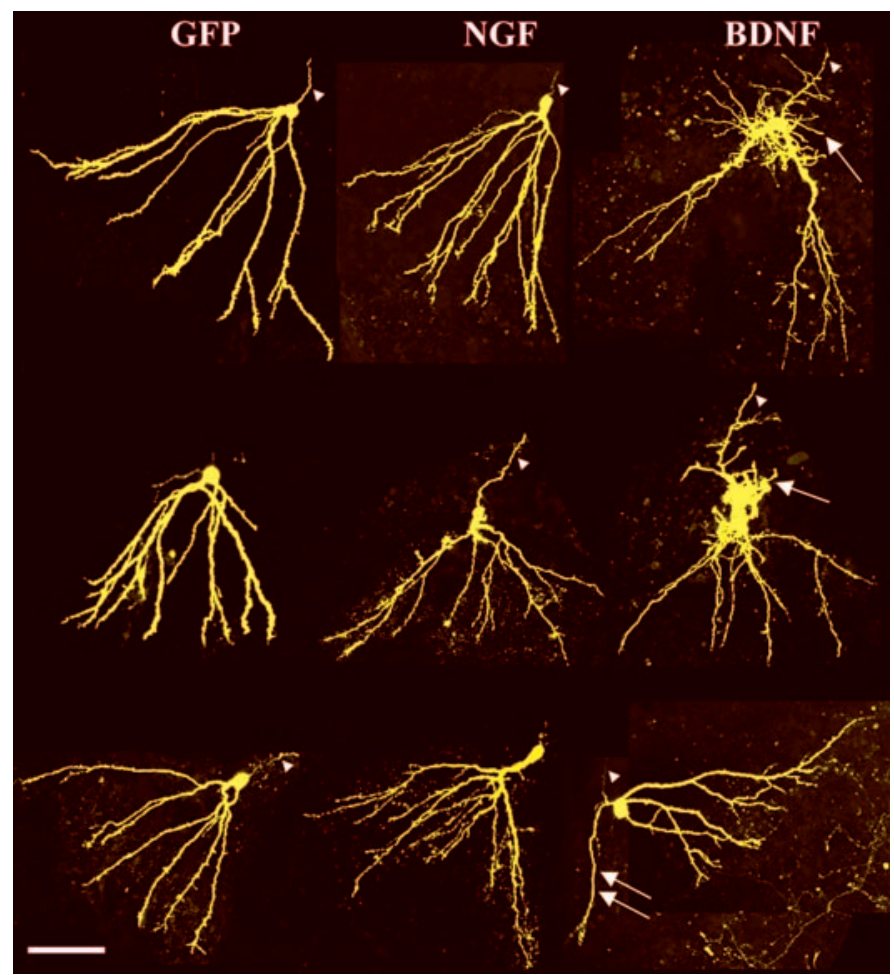

Figure 1. BDNF transfection induces dendritic and axonal sprouting around the soma. Shown is GFP immunoreactivity in DGCs transfected with GFP only (control), with GFP + NGF (control), or with GFP + BDNF. Arrows denote basal dendrites; arrowheads denote axons. Scale bar, $80 \mu \mathrm{m}$.

(Jandel, San Rafael, CA). In cases in which more than one neuron came from a given culture, the measurements for these neurons were averaged (except for the analysis of neuronal location). The number of slices used is therefore equivalent to the number of neurons that have been examined. Both parametric and nonparametric tests were used as appropriate. Dunn's posttest was used for ANOVAs on ranks. Medians and ranges are reported for nonnormally distributed data, and means and SE values are reported for data that passed the normality test. When used, the percentage of increase was calculated from the means.

\section{RESULTS}

\section{BDNF-transfected DGCs have abnormal dendritic fields and increased axonal branching}

The morphology of DGCs under control conditions as detected by GFP immunoreactivity was similar to that described in studies using Golgi (Ramon y Cajal, 1893; Lorente de No, 1934) or dye labeling of neurons (Claiborne et al., 1986, 1990). That is, the apical dendritic arbors of DGCs transfected with either GFP alone or GFP and NGF exhibited the characteristic fan-like spread with multiple branches emanating from the soma into the molecular layer and terminating at the hippocampal fissure (Fig. 1, left and middle columns, respectively). No obvious differences were detected between DGCs cotransfected with NGF and GFP compared with GFP alone (Fig. 1, compare neurons in left and middle columns).

In contrast to the morphological characteristics of control DGCs, transfection with BDNF resulted in a diversity of abnormalities evident even under casual inspection. The dendritic fields were altered profoundly, as evident in the appearance of basal dendrites emerging from the hilar margin of the DGC soma (Fig. 1, right column, arrows); moreover, the apical dendritic tree was
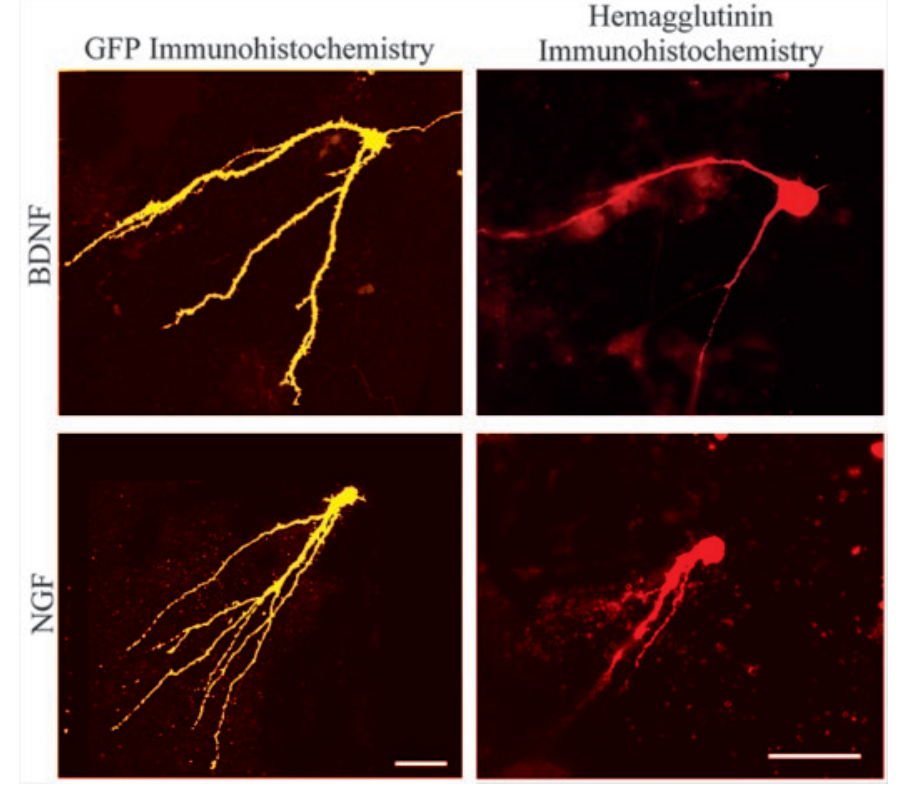

Figure 2. GFP fills the entire transfected neuron, whereas hemagglutinin (HA)-tagged neurotrophins are found primarily in the soma and proximal axons and dendrites. Shown is GFP and HA double labeling in DGCs transfected with GFP + BDNF (top) or GFP + NGF (bottom). The GFP images are confocal reconstructions, and the HA images are epifluorescent photomicrographs. Scale bars, $40 \mu \mathrm{m}$.

altered in that numerous short branches emanated from the soma and proximal dendritic tree, a pattern sharply contrasting with the fan-like arbor evident in control DGCs. In addition, the axons were altered in that numerous short branches were evident close to the soma, and the caliber of the main axon appeared to be increased relative to controls. In general, DGCs with striking dendritic changes also exhibited increased axonal branching and caliber.

To exclude the possibility that differences in NGF and BDNF expression were responsible for the overt differences in morphology between these groups, we assessed expression levels by immunostaining for the epitope tag HA. Similar levels of HA immunoreactivity were evident for BDNF- and NGF-transfected DGCs (Fig. 2, right panels) as assessed by gray scale analysis $[\mathrm{BDNF}=1130 \pm 214$ (means $\pm \mathrm{SEM}$ ); NGF $=990 \pm 246 ; p=$ 0.6 , Student's $t$ test], thereby demonstrating the specificity of the morphological consequences of BDNF expression. In addition, comparison of HA and GFP immunoreactivity in the same neurons revealed that HA immunoreactivity was much less intense than GFP immunoreactivity (Fig. 2). Whereas GFP immunoreactivity filled the entire neuron, HA immunoreactivity was found routinely only in the granule cell soma and proximal dendrites, less frequently in proximal axons (Fig. 2), and in only a single neuron in the distal axon (data not shown).

\section{BDNF effects on axonal branching: quantitative analyses}

In contrast to the paucity of branching of the proximal axon of control DGCs, proximal axons of BDNF-transfected DGCs exhibited increased numbers of branches (Fig. 3, top). Sholl analyses (Sholl, 1953) were used to quantify the number of axonal branch points within $100 \mu \mathrm{m}$ of the soma. These analyses disclosed a spatially specific effect of BDNF on branch number. That is, an approximately three- to fourfold increase in the number of pri- 


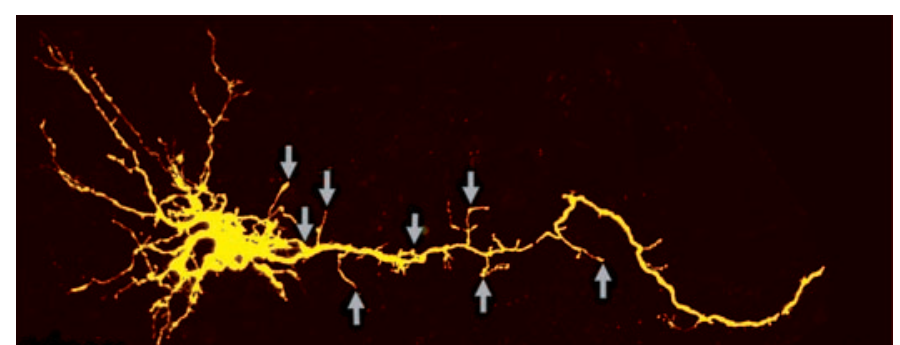

BDNF
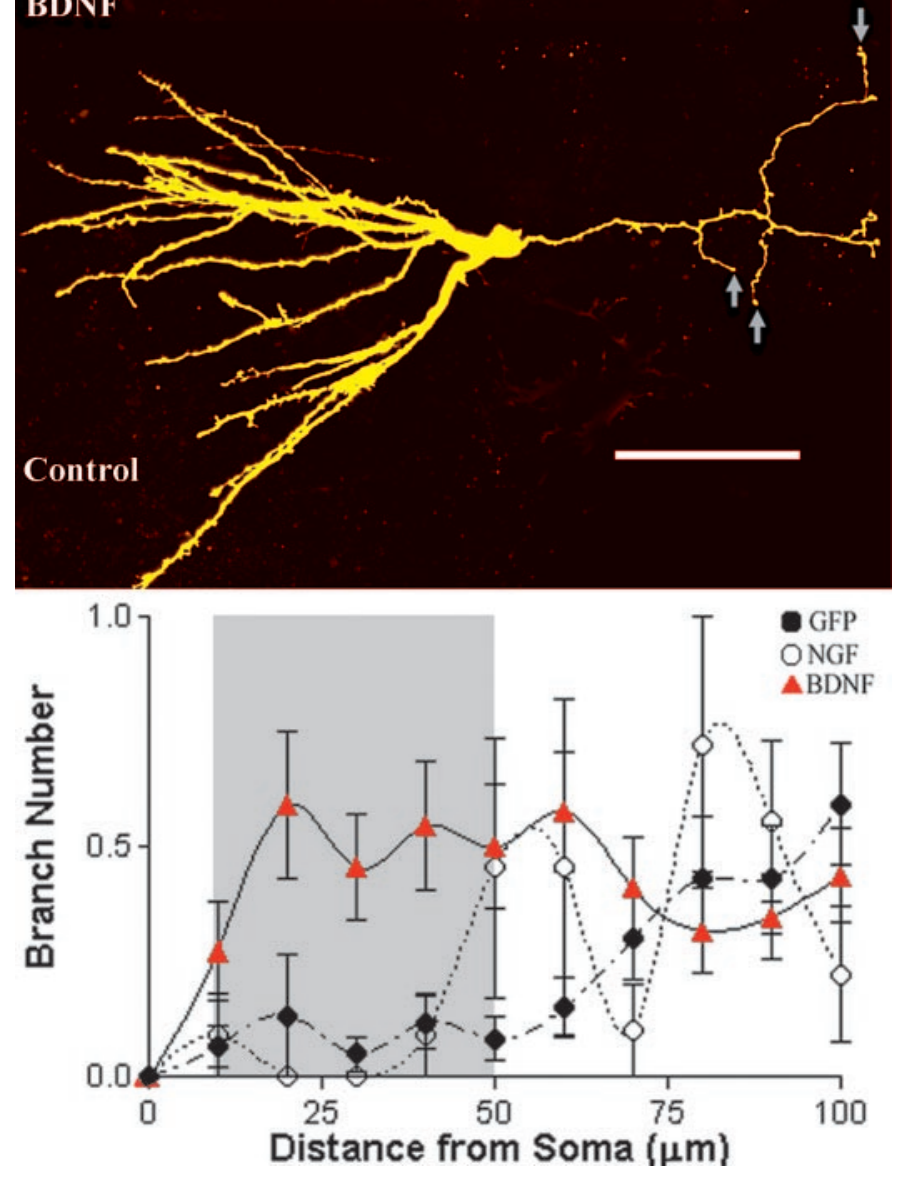

Figure 3. BDNF transfection increases the number of axonal branches within $50 \mu \mathrm{m}$ of the soma. Shown are confocal reconstructions of DGCs transfected with GFP + BDNF or GFP + PCDNA-3 (empty vector control). Top, Arrows denote axonal branches. Scale bar, $70 \mu \mathrm{m}$. Bottom, A Sholl analysis of axonal branch points. Values are the means \pm SEM. Lines connecting the data points were calculated with a cubic spline fit. Data within the shaded region were pooled for statistical analysis $(p<$ 0.001; BDNF vs GFP and NGF).

mary axon branches was evident within $50 \mu \mathrm{m}$ of the somata of BDNF-transfected neurons $(n=33)$ compared with NGFtransfected $(n=11)$ or GFP-transfected $(n=30)$ neurons (Fig. 3, bottom, Table 1) (a priori ANOVA on ranks; $p<0.001$ compared with GFP and NGF). These additional branches tended to be short $(10-50 \mu \mathrm{m})$ and typically did not cross the granule cell layer (see Figs. 1, 3, 5). The effect of BDNF was restricted to the first $50 \mu \mathrm{m}$ as evident in the similar numbers of branches in the three groups between 50 and $100 \mu \mathrm{m}$ from the soma (Fig. 3, Table 1). No significant differences in the furthest region of stratum lucidum reached by the longest axon collateral or in the number of giant mossy fiber boutons were detected among the three groups
(Table 1). Finally, axon caliber appeared to be increased in BDNF-transfected DGCs relative to GFP- and NGF-transfected granule cells (Figs. 1, 3), but this was not quantified.

\section{BDNF induces the formation of basal dendrites and increases dendritic branching around the somata of DGCs}

BDNF increased the number of dendritic processes relatively uniformly around the somata of transfected DGCs (see Figs. 1, 5). This uniformity was striking because the DGCs are polar neurons. Dendrites typically originate only from the apical side of the soma; the basal (hilar) side of the soma typically is devoid of dendrites. Indeed, the majority of GFP- and NGF-transfected DGCs were devoid of basal dendrites; in the remainder (12\% of GFP- and $30 \%$ of NGF-transfected DGCs) a single basal dendrite was observed. The pattern evident in both the GFP- and NGF-transfected DGCs is similar to that described previously in Golgi studies of normal brain and slice culture (Seress and Pokorny, 1981; Seress and Ribak, 1990; Heimrich and Frotscher, 1991; Zafirov et al., 1994). The results with BDNF stand in sharp contrast to GFP and NGF. That is, basal dendrites were evident in a majority $(74 \%)$ of BDNF-transfected DGCs, and the majority of these (71\%) exhibited multiple, not single, basal dendrites (Fig. 4, top left). BDNF likewise produced striking increases in the length of the basal dendrites in comparison to GFP or NGF (Fig. 4, top right). For BDNF-transfected neurons the median basal dendrite length was $170 \mu \mathrm{m}$, whereas GFP- and NGFtransfected neurons had medians of zero.

Within the apical dendritic field BDNF transfection also increased the number of short dendritic processes around the soma. Because DGCs normally possess apical dendrites, however, this increase manifested slightly differently (relative to the basal dendritic field). Rather than increasing the number of primary apical dendrites (those dendrites that originate from the apical side of the soma), BDNF transfection led to increased branching of primary apical dendrites. Thus the number of primary apical dendrites was not altered among treatment groups (Table 2), but the number of branches off the apical dendrites (secondary dendrites) was increased in regions close to the soma (Fig. 5).

To quantify the increase of short dendritic processes around the somata of BDNF-transfected DGCs for both the apical and basal dendritic fields combined, we determined the number of dendritic terminations at given distances from the soma. By definition, short dendritic processes originating from the soma or proximal dendrites will terminate close to the soma, and long dendrites that extend substantial distances (as is typical of control DGCs) will terminate far from the soma. This measure, therefore, provides a means to quantify the observed differences in the dendritic fields among groups. Indeed, BDNF-transfected neurons possessed large numbers of dendritic processes that ended within $50 \mu \mathrm{m}$ of the soma (Fig. 4, bottom). In contrast, dendrites from GFP- and NGF-transfected DGCs tended to extend $\sim 175$ $\mu \mathrm{m}$ from the soma before ending (Fig. 4, bottom). A statistical analysis comparing the number of dendritic endings within $50 \mu \mathrm{m}$ of the cell body revealed a significant increase in ending number for BDNF-transfected DGCs relative to GFP- and NGFtransfected cells (Table 2, a priori ANOVA on ranks; $p<0.001$ ). No change was found between 50 and $100 \mu \mathrm{m}$. The increase within $50 \mu \mathrm{m}$ represents an $\sim 6000 \%$ increase over GFPtransfected and a $700 \%$ increase over NGF-transfected neurons. 
Table 1. Somatic and axonal properties of dentate granule cells

\begin{tabular}{|c|c|c|c|c|c|}
\hline Treatment & Soma area & $\begin{array}{l}\text { Furthest region reached } \\
\text { by axon (semiquantitative) }\end{array}$ & $\begin{array}{l}\text { Giant mossy fiber } \\
\text { bouton number }\end{array}$ & $\begin{array}{l}\text { Branch number* } \\
(0-50 \mu \mathrm{m})\end{array}$ & $\begin{array}{l}\text { Branch number* } \\
(50-100 \mu \mathrm{m})\end{array}$ \\
\hline GFP & $73.5(46-109)(n=14)$ & $3(1-5)(n=14)$ & $0.50(0-12)(n=14)$ & $0(0-5)(n=30)$ & $2.0(0-8)(n=29)$ \\
\hline $\mathrm{GFP}+\mathrm{NGF}$ & $69.5(50-174)(n=10)$ & $2(1-5)(n=9)$ & $0.00(0-8)(n=9)$ & $0(0-4)(n=11)$ & $2.5(0-5)(n=6)$ \\
\hline $\mathrm{GFP}+\mathrm{BDNF}$ & $90.4(45-200)(n=19)$ & $3(2-5)(n=18)$ & $0.75(0-6)(n=18)$ & $2.0(0-8)^{* *}(n=33)$ & $2.0(0-5)(n=31)$ \\
\hline
\end{tabular}

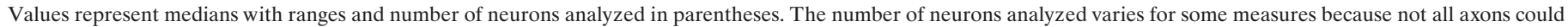
be reconstructed.

* Data from all experiments combined.

**Significantly different from GFP and GFP + NGF; $p<0.001$.
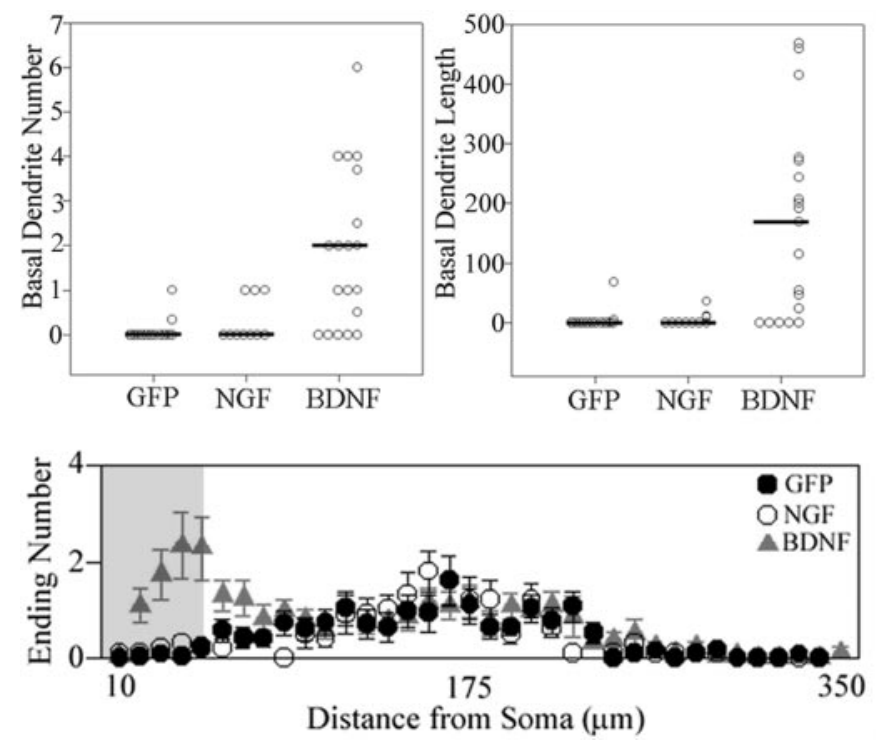

Figure 4. BDNF increases basal dendrite number and length. BDNFtransfected DGCs have increased numbers of basal dendrites (top left; $p<$ 0.001 ) and increased basal dendrite length (top right; $p<0.001$ ) relative to GFP- and NGF-transfected neurons. Black bars represent median scores. Open circles represent the values from individual neurons. Fractions result from the averaging of neurons from the same culture to avoid pseudoreplication. The bottom panel depicts a Sholl analysis examining the number of dendritic endings at a given distance from the soma. BDNF-transfected neurons have increased numbers of dendrites, which end 10-50 $\mu \mathrm{m}$ from the soma. Values are the means \pm SEM. Data within the shaded region were pooled for statistical analysis ( $p<0.001$; BDNF vs GFP and NGF).

Approximately $60 \%$ of this effect was the result of changes in the apical dendritic field, with the remainder resulting from changes in the basal dendritic field (Table 3).

In contrast to these effects on short dendritic processes, BDNF did not significantly modify soma area, apical dendrite number, total number of branches off apical dendrites (despite the increased branch number within $50 \mu \mathrm{m}$ of the soma, as in Fig. 4, bottom), or total (the combined length of all apical dendrites and their branches) and mean (total apical dendrite length divided by the number of primary apical dendrites) apical dendritic lengths in comparison to NGF or GFP (Tables 1, 2). There were also no overt differences in dendritic spine number, although this parameter was not examined systematically. Finally, although the apical dendritic fields of BDNF-transfected cells often were disorganized in comparison to GFP- or NGF-transfected cells (Figs. 1, 3 ), there were no significant differences in the transverse spread of the apical dendrites nor the depth into the molecular layer reached by the longest dendrite.

\section{Morphological effects of BDNF are cell type-specific} In contrast to its effects on DGCs, BDNF did not modify the number of apical or basal dendrites of CA3 or CA1 pyramidal cells in comparison to GFP or NGF (Table 4). The cell type specificity of BDNF is unlikely to be attributable to differences in BDNF protein levels, because considerable overlap in BDNF levels exists between DGCs and pyramidal cells as assessed by quantitative gray scale analysis of epitope tag immunohistochemistry (data not shown).

\section{The effect of BDNF on granule cell dendritic morphology is receptor tyrosine kinase-dependent}

To determine whether BDNF increased granule cell basal dendrite number by activating a tyrosine kinase, we examined the effects of the Trk receptor tyrosine kinase inhibitor K252a. BDNF produced a striking increase in the number of DGCs exhibiting basal dendrites in comparison to GFP alone (Fig. 6), thereby confirming the results of earlier experiments (Fig. 4). Inclusion of K252a (200 nM) in the BDNF-transfected cultures resulted in a significant reduction of the number of DGCs with basal dendrites (Fig. 6). The median basal dendrite number of DGCs in the GFP $(n=19), \operatorname{GFP}+\mathrm{K} 252 \mathrm{a}(n=22)$, BDNF $(n=$ $16)$, and $\mathrm{BDNF}+\mathrm{K} 252 \mathrm{a}(n=15)$ groups were $0,0.42,2.5$, and 0 , respectively (ANOVA on ranks; $p<0.001$ ). Similarly, BDNFtransfected DGCs (median, 3.0) had significantly more axonal branches within $50 \mu \mathrm{m}$ of the soma than GFP-transfected control granule cells (median, 0.0), whereas BDNF+K252a-treated granule cells (median, 1.0) were not different from these controls.

\section{DGCs with the most robust morphological changes are closest to the hilus}

Despite similar levels of expression as assessed by HA immunoreactivity, heterogeneity was noted with respect to the morphological consequences of BDNF expression in DGCs. Some DGCs exhibited robust increases in axonal branches and basal dendrites, whereas others were indistinguishable from controls (Fig. 4, top panels). Further examination of the transfected DGCs revealed that cells close to the hilar/granule cell layer border tended to exhibit robust BDNF-induced changes, whereas the morphology of DGCs farther from this border (closer to the molecular layer) tended to appear normal. To quantify this effect, we correlated the distance of the DGCs from the hilar/granule cell layer border with the number of dendritic endings within $50 \mu \mathrm{m}$ of the soma, a robust indicator of BDNF response. A Spearman Rank Order Correlation revealed a significant negative interaction between distance from the hilus and ending number (Fig. 7) $(r=-0.528$; $p<0.01)$. That is, neurons closest to the hilus exhibited the greatest number of endings within $50 \mu \mathrm{m}$ of the cell body and therefore looked the most abnormal. Interestingly, a few of the DGCs in the BDNF group actually were located within the hilus, 
Table 2. Properties of dentate granule cells (apical dendrites and apical and basal combined)

\begin{tabular}{lllllll} 
Treatment & $\begin{array}{l}\text { Primary apical } \\
\text { dendrite number }\end{array}$ & $\begin{array}{l}\text { Apical dendrite } \\
\text { branch number }\end{array}$ & $\begin{array}{l}\text { Apical dendrite } \\
\text { length }(\text { total } \mu \mathrm{m})\end{array}$ & $\begin{array}{l}\text { Apical dendrite } \\
\text { length }(\text { mean } \mu \mathrm{m})\end{array}$ & $\begin{array}{l}\text { Number of dendritic } \\
\text { endings }(0-50 \mu \mathrm{m})\end{array}$ & $\begin{array}{l}\text { Total number of } \\
\text { dendritic endings }\end{array}$ \\
\hline GFP $(n=14)$ & $2.34 \pm 0.29$ & $13.5(8-20)$ & $1542 \pm 116$ & $649(411-2429)$ & $0(0-1)$ & $16.0(10-21)$ \\
GFP + NGF $(n=10)$ & $2.30 \pm 0.30$ & $15(7-26)$ & $1461 \pm 165$ & $668(297-1673)$ & $0(0-3)$ \\
GFP + BDNF $(n=19)$ & $2.11 \pm 0.23$ & $16(6-52)$ & $1444 \pm 130$ & $616(284-2163)$ & $3.5(0-29)^{* *}$ & $20.0(10-56)^{*}$ \\
\hline
\end{tabular}

Median (range). Mean \pm SEM.

*Significantly different from GFP; $p<0.05$; log transformation.

**Significantly different from GFP and GFP + NGF; $p<0.001$.
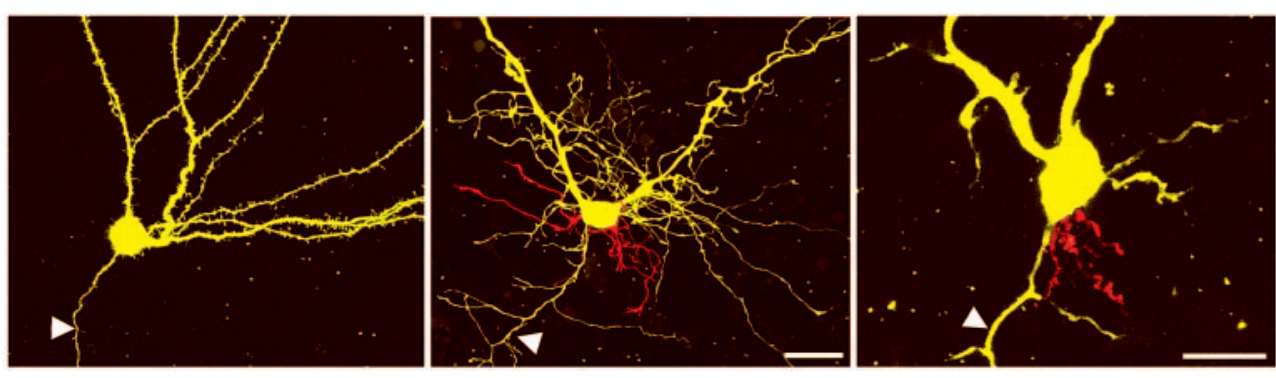

Figure 5. BDNF transfection increases the number of primary basal dendrites and the number of apical dendritic branches. Left, Control GFP-transfected neuron with no basal dendrites and one apical dendritic branch terminating close to the soma. Middle and right, BDNF-transfected granule cells with numerous basal dendrites (shown in red) and many apical dendritic branches terminating close to the soma. $A r$ rowheads denote axons. Scale bars, $20 \mu \mathrm{m}$.

Table 3. Properties of dentate granule cell basal dendrites

\begin{tabular}{llcl} 
Treatment & $\begin{array}{l}\text { Basal dendrite } \\
\text { number }\end{array}$ & $\begin{array}{l}\text { Basal dendrite length } \\
(\text { total } \mu \mathrm{m})\end{array}$ & $\begin{array}{c}\text { Number of branches } \\
\text { (basal dendrites })\end{array}$ \\
\hline GFP $(n=14)$ & $0(0-1)$ & $0(0-67.5)$ & $0(0-0.33)$ \\
GFP + NGF $(n=10)$ & $0(0-1)$ & $0(0-35.6)$ & $0(0-0)$ \\
GFP + BDNF $(n=19)$ & $2(0-6)^{* *}$ & $168.6(0-468.6)^{* *}$ & $2(0-12)^{* *}$ \\
\hline
\end{tabular}

Median (range).

**Significantly different from GFP and GFP + NGF; $p<0.001$.

Table 4. Properties of CA1 and CA3 pyramidal cells

CA1 pyramidal cells

\begin{tabular}{llllllll} 
Treatment & $\begin{array}{l}\text { Primary apical } \\
\text { dendrite number }\end{array}$ & $\begin{array}{l}\text { Primary basal } \\
\text { dendrite number }\end{array}$ & $\begin{array}{l}\text { Number of dendritic } \\
\text { endings }(0-50 \mu \mathrm{m})\end{array}$ & & $\begin{array}{l}\text { Primary apical } \\
\text { dendrite number }\end{array}$ & $\begin{array}{l}\text { Primary basal } \\
\text { dendrite number }\end{array}$ & $\begin{array}{l}\text { Number of dendritic } \\
\text { endings }(0-50 \mu \mathrm{m})\end{array}$ \\
\hline GFP & $1(1-5)(n=28)$ & $3(1-7)$ & $2(0-14)$ & & $1(1-3.3)(n=19)$ & $3.0 \pm 0.3$ & \\
GFP + NGF & $1.5(1-2)(n=12)$ & $2.5(1-4)$ & Not determined & & $1(1-5)(n=11)$ & $3.3 \pm 0.3$ & \\
GFP + BDNF & $1.9(1-4)(n=24)$ & $3(1-6)$ & $3(0-22)$ & $1.5(1-2)(n=11)$ & $4 \pm 0.4$ & $1(0-3)$
\end{tabular}

Median (range). Mean \pm SEM.

a finding reminiscent of the hilar ectopic DGCs described in several recent reports of epileptic animals (Parent et al., 1997; Scharfman et al., 2000; Dashtipour et al., 2001) and humans (Houser, 1990). Like the in vivo findings, hilar DGCs in the present study had an axon in stratum lucidum [a feature thought to be exclusive to DGCs (Ramon y Cajal, 1893; Lorente de No, 1934)], had small cell bodies (also characteristic of DGCs), and exhibited numerous basal dendrites. By contrast, no DGCs were found within the hilus of control animals. There was also no correlation between dendritic endings and distance from the hilus for GFP-transfected (Fig. 7) $(r=0.493 ; p>0.05)$ and NGFtransfected (Fig. 7) $(r=0.487 ; p>0.05)$ DGCs. A similar location analysis found no correlation between ending number and the distance a BDNF-transfected DGC was from the tip of the superior blade of the granule cell layer (medial-to-lateral location, $r=0.260 ; p>0.05$; data not shown).
A correlation analysis of axonal branch points within $50 \mu \mathrm{m}$ of the soma revealed a similar effect. Within the BDNF-treated group the DGCs closest to the hilus had the greatest number of axonal branch points (Spearman Rank Order Correlation, $r=$ $-0.516 ; p=0.003$ ) (Fig. 7). In contrast, no significant correlations were found between location and axonal branch number for either GFP-transfected $(r=-0.15 ; p=0.4)$ or NGF-transfected $(r=0.04 ; p=0.9)$ granule cells.

\section{Differences in DGC location and survival cannot account for the morphological differences}

Quantitative analysis of DGC location and cell number demonstrates that the differences among the experimental groups are unlikely to be explained by location-dependent differences in morphology or selective survival. For each DGC the distance of the soma from the tip of the superior blade of the dentate 


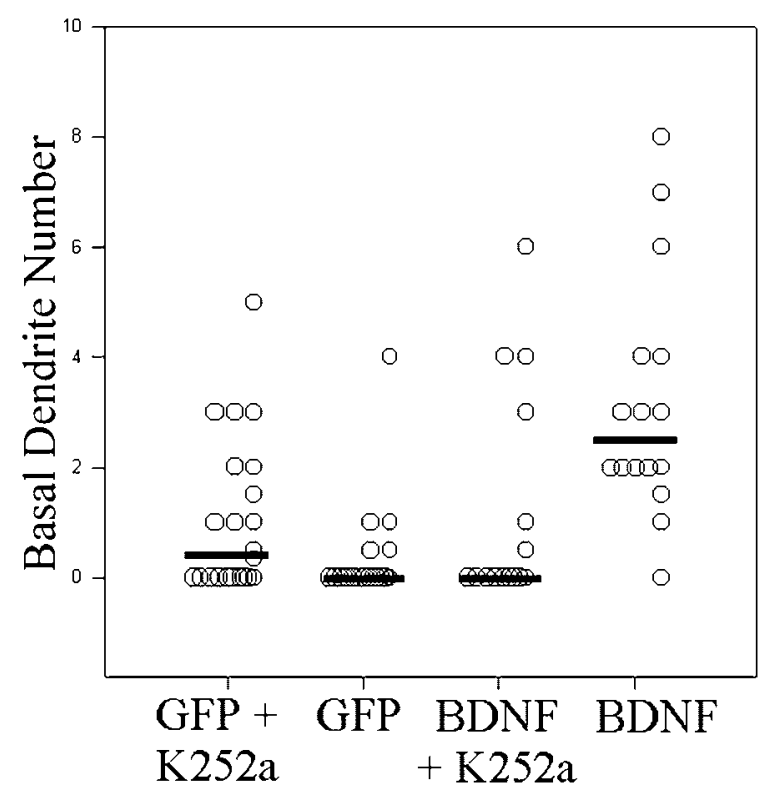

Figure 6. The BDNF effects on DGCs are tyrosine kinase receptor dependent. Treatment with $200 \mathrm{~nm} \mathrm{K252a}$ blocks the effect of BDNF transfection on basal dendrite number. Black bars represent median scores. Open circles represent the values from individual neurons. BDNFtransfected neurons had significantly more basal dendrites than GFPtransfected neurons or GFP- and BDNF-transfected neurons treated with $\mathrm{K} 252 \mathrm{a}(p<0.001)$. Fractions result from the averaging of neurons from the same culture to avoid pseudoreplication.
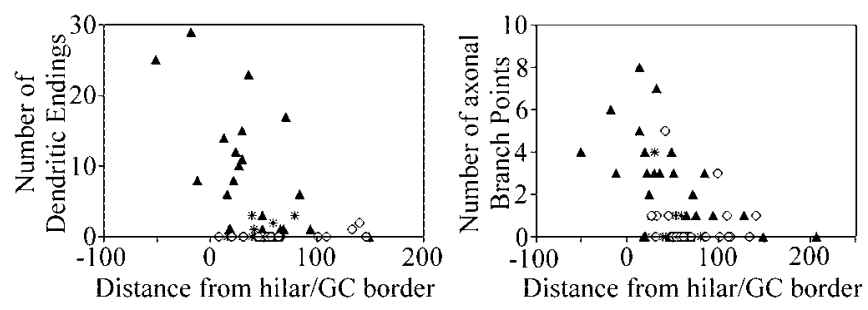

Figure 7. DGCs closest to the hilus are most responsive to BDNF transfection. Shown are correlations between the number of dendritic endings (left) and axonal branch points (right) within $50 \mu \mathrm{m}$ of the soma and the distance the soma was from the hilar/granule cell layer border. Triangles represent the values for individual BDNF-transfected DGCs. Open circles and asterisks represent GFP- and NGF-transfected neurons, respectively. The correlation coefficients for the BDNF groups were $-0.528(p<0.01)$ for dendritic endings and $-0.516(p<0.01)$ for axonal branch points.

(medial-to-lateral position) and from the hilar/granule cell layer border was determined. There were no systematic differences in DGC location that could account for the differences in morphologic patterns among the three groups (data not shown). Furthermore, an analysis examining the number of transfected DGCs per explant found no differences among treatment groups (medians for GFP, NGF, and BDNF all $=0$; range $=0-4,0-2$, and $0-4$, respectively), arguing that differences in survival cannot account for the differences in morphologic patterns among the three groups.

\section{DISCUSSION}

The principal findings are fivefold. First, transfection with BDNF, but not NGF, increased axonal branching and formation of basal dendrites of DGCs. Second, the effects of BDNF were specific to granule cells in that similar alterations were not detected in CA3 or CA1 pyramidal cells. Third, the effects of BDNF on DGC morphology were most robust close to the soma, the region most immunoreactive for the epitope-tagged BDNF. Fourth, the effects of BDNF were eliminated by the tyrosine kinase inhibitor K252a. Finally, a significant correlation was found in that the effects of BDNF were marked most on DGCs located close to the border of the hilus with the granule cell layer. Together, these findings demonstrate that increased expression of BDNF in DGCs, an occurrence common to human limbic epilepsy as well as its animal models, is sufficient to induce two distinctive morphological features of these neurons identified in an epileptic brain, namely the formation of basal dendrites and axonal sprouting.

Previous work from our laboratory and others suggested that BDNF may have morphoregulatory effects on DGCs. For example, the bath application of BDNF to dentate gyrus neurons in primary culture or coculture with CA3 minislices increased axonal length, number, and branching (Patel and McNamara, 1995; Lowenstein and Arsenault, 1996a,b); whether the neurons that were identified were in fact DGCs and whether the effects of BDNF were direct or indirect were not clear from these studies. The experimental approach that was used here permitted unambiguous identification of DGCs. Second, in contrast to cultures on coated plates or in a collagen matrix (Patel and McNamara, 1995; Lowenstein and Arsenault, 1996a,b), the explant method that was used here more nearly approximates the in vivo condition by retaining some of the afferent and efferent connections as well as some of the molecular cues of the extracellular milieu such as cell adhesion molecules and extracellular matrix proteins. Finally, instead of bath application, the present approach more nearly approximated the in vivo condition during epileptogenesis by increasing the expression of BDNF within individual DGCs via transfection. The CMV promoter used to drive BDNF expression in the present study markedly increases BDNF levels, but whether these increases match those evident in vivo during epileptogenesis is uncertain. That is, quantitation of BDNF content in homogenates of hippocampus during epileptogenesis discloses increases as high as $400 \%$ of control (Nawa et al., 1995) (see also Elmer et al., 1998; Rudge et al., 1998); because immunohistochemical analyses reveal that the greatest increases are within the granule cells (Wetmore et al., 1994; Yan et al., 1997; Vezzani et al., 1999), which account for $<20 \%$ of hippocampal protein (Byrne et al., 1980), the $400 \%$ increase is almost certainly an underestimate of the increase of BDNF within granule cells. The ability to drive marked increases of BDNF appears to be critical, because only marginal increases $(32 \%)$ recently described in transgenic mice (Croll et al., 1999) were not associated with robust effects on indirect histochemical measures of axonal sprouting (Qiao et al., 2001).

The advantages inherent in the experimental approach used here permitted demonstration that increased expression of BDNF within a DGC was sufficient to recapitulate some of the morphological plasticities of the DGCs in the epileptic brain. For example, the increased expression of BDNF described here triggered increased branching of mossy fiber axons within $50 \mu \mathrm{m}$ of the cell soma, a finding similar to earlier descriptions of increased branching of biocytin-labeled DGC axons in the dentate hilus in vivo in the kainic acid model of epilepsy (Buckmaster and Dudek, 1999). Likewise, the increased expression of BDNF triggered the formation of basal dendrites, a plasticity similar to that described in vivo in the kindling, kainic acid, and pilocarpine models of 
epilepsy (Spigelman et al., 1998; Buckmaster and Dudek, 1999; Ribak et al., 2000). Basal dendrites are of particular interest because their close intermingling with a rich network of mossy fiber axons of granule cells in the dentate hilus facilitates the formation of excitatory synapses between or even within the same DGC, as demonstrated by electron microscopy (Ribak et al., 2000; Dashtipour et al., 2002).

Whereas the BDNF-induced formation of basal dendrites and sprouting of the proximal axon of DGCs are concordant with findings in granule cells in animal models of epilepsy (Spigelman et al., 1998; Buckmaster and Dudek, 1999; Ribak et al., 2000), the invasion of sprouted axons into the inner molecular layer of the dentate gyrus or into stratum oriens of CA3 as described in the epileptic brain (Sutula et al., 1988; Represa and Ben-Ari, 1992) was not detected in the present study. This discrepancy simply may reflect the short time period that was examined in the present study. Mossy fiber sprouting develops over weeks in vivo; thus it seems unlikely that such sprouting would develop in our preparation in the $24 \mathrm{hr}$ time period examined, especially given that high BDNF levels are present only for the latter portion of that period. Importantly, however, Wenzel et al. (2000) noted that in epileptic animals mossy fibers tended to sprout from the main axon within a short distance from the soma. The increased axonal branching observed in the present study, therefore, is consistent with what one would expect to observe in the early stages of mossy fiber sprouting.

A notable feature of the present study was the striking cellular specificity of the morphological effects of BDNF among neurons within the hippocampus. Transfection with BDNF produced robust morphological changes of DGCs, but not of CA1 or CA3 pyramidal cells. Indeed, even among DGCs, transfection with BDNF produced striking effects in the subset of neurons near the margin of the hilus and the granule cell layer; more subtle or no detectable effects were found on granule cells located closer to the molecular layer. Interestingly, this finding parallels in vivo findings that used the pilocarpine model of epilepsy in which basal dendrites were most numerous on DGCs located at the hilar/ granule cell layer border (Ribak et al., 2000; Dashtipour et al., 2002). It seems plausible that differences in neuronal age might account for this pattern of responding and nonresponding neurons. CA1 and CA3 pyramidal cells are born earlier than DGCs (Altman and Bayer, 1990a), and newborn and young granule cells reside closer to the margin of the hilus and granule cell layer (Altman and Das, 1965; Altman and Bayer, 1990b). A correlation exists, therefore, suggesting that young DGCs may be more responsive to BDNF than older granule cells. Although the mechanistic basis of any developmental changes in BDNF sensitivity is not obvious, the TrkB receptor may play a role. The effects of transfected BDNF likely were mediated by the activation of TrkB, because the tyrosine kinase inhibitor K252a eliminated the morphological changes. An alternative explanation, activation of the p75 receptor, is unlikely both because of the lack of effect of transfected NGF and the elimination of BDNF effects by K252a. Developmental differences in the levels of expression of the TrkB receptor, and in particular its noncatalytic, truncated isoform, therefore may play a role in the cellular specificity of BDNF (Dugich-Djordjevic et al., 1993; Escandon et al., 1994; Knusel et al., 1994; Fryer et al., 1996). Interestingly, increased immunoreactivity for the polysialylated form of neural cell adhesion molecule (NCAM) is evident in developing DGCs (Seki and Arai, 1991; Parent et al., 1999; Seki and Arai, 1999), which might contribute to an increased responsiveness to BDNF, because
PSA-NCAM increases the potency of BDNF in activating TrkB (Muller et al., 2000; Vutskits et al., 2001).

In summary, repeated and/or prolonged focal hippocampal seizures promote limbic epileptogenesis, the process by which a normal brain becomes epileptic (Goddard et al., 1969). The cascade of gene expression activated by focal hippocampal seizures includes marked increases of BDNF content in multiple neuronal populations including the DGCs (Wetmore et al., 1994; Smith et al., 1997; Yan et al., 1997; Vezzani et al., 1999). Pharmacological and genetic interventions implicate a causal role for BDNF in epileptogenesis (Kokaia et al., 1995; Binder et al., 1999a; Lahteinen et al., 2002; Scharfman et al., 2002). Here we show that increasing the expression of BDNF in DGCs is sufficient to induce the formation of basal dendrites and axonal sprouting. The morphological consequences of increased BDNF expression may underlie the recurrent excitatory synapses demonstrated among DGCs in epileptic animals (Molnar and Nadler, 1999; Wuarin and Dudek, 2001) and thus may constitute one mechanism by which seizure-induced BDNF expression promotes limbic epileptogenesis. Our findings provide the rationale for determining whether increased BDNF expression is sufficient and/or necessary for the morphological and physiological plasticities of the granule cells during epileptogenesis in vivo and, if so, for elucidating the role of such plasticities in epileptogenesis. Analyses of the morphological plasticities of the granule cells in mice carrying mutations of BDNF and TrkB genes will provide an initial approach to addressing these questions.

\section{REFERENCES}

Altman J, Bayer SA (1990a) Mosaic organization of the hippocampal neuroepithelium and the multiple germinal sources of dentate granule cells. J Comp Neurol 301:325-342.

Altman J, Bayer SA (1990b) Migration and distribution of two populations of hippocampal granule cell precursors during the perinatal and postnatal periods. J Comp Neurol 301:365-381.

Altman J, Das GD (1965) Autoradiographic and histological evidence of postnatal hippocampal neurogenesis in rats. J Comp Neurol 124: 319-335.

Babb TL, Kupfer WR, Pretorius JK, Crandall PH, Levesque MF (1991) Synaptic reorganization by mossy fibers in human epileptic fascia dentata. Neuroscience 42:351-363.

Behr J, Lyson KJ, Mody I (1998) Enhanced propagation of epileptiform activity through the kindled dentate gyrus. J Neurophysiol 79:1726-1732.

Binder DK, Routbort MJ, Ryan TE, Yancopoulos GD, McNamara JO (1999a) Selective inhibition of kindling development by intraventricular administration of TrkB receptor body. J Neurosci 19:1424-1436.

Binder DK, Routbort MJ, McNamara JO (1999b) Immunohistochemical evidence of seizure-induced activation of Trk receptors in the mossy fiber pathway of adult rat hippocampus. J Neurosci 19:4616-4626.

Buckmaster PS, Dudek FE (1999) In vivo intracellular analysis of granule cell axon reorganization in epileptic rats. J Neurophysiol 81:712-721.

Byrne MC, Gottlieb R, McNamara JO (1980) Amygdala kindling induces muscarinic cholinergic receptor declines in a highly specific distribution within the limbic system. Exp Neurol 69:85-98.

Claiborne BJ, Amaral DG, Cowan WM (1986) A light and electron microscopic analysis of the mossy fibers of the rat dentate gyrus. J Comp Neurol 246:435-458.

Claiborne BJ, Amaral DG, Cowan WM (1990) Quantitative, threedimensional analysis of granule cell dendrites in the rat dentate gyrus. J Comp Neurol 302:206-219.

Collins RC, Tearse RG, Lothman EW (1983) Functional anatomy of limbic seizures: focal discharges from medial entorhinal cortex in rat. Brain Res 280:25-40.

Croll SD, Suri C, Compton DL, Simmons MV, Yancopoulos GD, Lindsay RM, Wiegand SJ, Rudge JS, Scharfman HE (1999) Brain-derived neurotrophic factor transgenic mice exhibit passive avoidance deficits, increased seizure severity, and in vitro hyperexcitability in the hippocampus and entorhinal cortex. Neuroscience 93:1491-1506.

Dashtipour K, Tran PH, Okazaki MM, Nadler JV, Ribak CE (2001) Ultrastructural features and synaptic connections of hilar ectopic granule cells in the rat dentate gyrus are different from those of granule cells in the granule cell layer. Brain Res 890:261-271.

Dashtipour K, Yan X-X, Dinh TT, Okazaki MM, Nadler JV, Ribak CE (2002) Quantitative and morphological analysis of dentate granule 
cells with recurrent basal dendrites from normal and epileptic rats. Hippocampus 12:235-244.

Dugich-Djordjevic MM, Ohsawa F, Hefti F (1993) Transient elevation in catalytic TrkB mRNA during postnatal development of the rat brain. NeuroReport 4:1091-1094.

Elmer E, Kokaia Z, Kokaia M, Carnahan J, Nawa H, Lindvall O (1998) Dynamic changes of brain-derived neurotrophic factor protein levels in the rat forebrain after single and recurring kindling-induced seizures. Neuroscience 83:351-362.

Escandon E, Soppet D, Rosenthal A, Mendoza-Ramirez JL, Szonyi E, Burton LE, Henderson CE, Parada LF, Nikolics K (1994) Regulation of neurotrophin receptor expression during embryonic and postnatal development. J Neurosci 14:2054-2068.

Franck JE, Pokorny J, Kunkel DD, Schwartzkroin PA (1995) Physiologic and morphologic characteristics of granule cell circuitry in human epileptic hippocampus. Epilepsia 36:543-558.

Frotscher M, Zimmer J (1983) Lesion-induced mossy fibers to the molecular layer of the rat fascia dentata: identification of postsynaptic granule cells by the Golgi-EM technique. J Comp Neurol 215:299-311.

Fryer RH, Kaplan DR, Feinstein SC, Radeke MJ, Grayson DR, Kromer LF (1996) Developmental and mature expression of full-length and truncated TrkB receptors in the rat forebrain. J Comp Neurol 374:21-40.

Gall CM (1993) Seizure-induced changes in neurotrophin expression: implications for epilepsy. Exp Neurol 124:150-166.

Gall CM, Isackson PJ (1989) Limbic seizures increase neuronal production of messenger RNA for nerve growth factor. Science 245:758-761.

Goddard GV, McIntyre DC, Leech CK (1969) A permanent change in brain function resulting from daily electrical stimulation. Exp Neurol 25:295-330.

He XP, Minichiello L, Klein R, McNamara JO (2002) Immunohistochemical evidence of seizure-induced activation of TrkB receptors in the mossy fiber pathway of adult mouse hippocampus. J Neurosci 22:7502-7508.

Heimrich B, Frotscher M (1991) Differentiation of dentate granule cells in slice cultures of rat hippocampus: a Golgi/electron microscopic study. Brain Res 538:263-268.

Horch HW, Kruttgen A, Portbury SD, Katz LC (1999) Destabilization of cortical dendrites and spines by BDNF. Neuron 23:353-364.

Houser CR (1990) Granule cell dispersion in the dentate gyrus of humans with temporal lobe epilepsy. Brain Res 535:195-204.

Knusel B, Rabin SJ, Hefti F, Kaplan DR (1994) Regulated neurotrophin receptor responsiveness during neuronal migration and early differentiation. J Neurosci 14:1542-1554.

Kokaia M, Ernfors P, Kokaia Z, Elmer E, Jaenisch R, Lindvall O (1995) Suppressed epileptogenesis in BDNF mutant mice. Exp Neurol 133:215-224.

Lahteinen S, Pitkanen A, Saarelainen T, Nissinen J, Koponen E, Castren $\mathrm{E}$ (2002) Decreased BDNF signaling in transgenic mice reduces epileptogenesis. Eur J Neurosci 15:721-734.

Lorente de No R (1934) Studies on the structure of the cerebral cortex. II. Continuation of the study of the ammonic system. J Psychol Neurol 46:113-177.

Lowenstein DH, Arsenault L (1996a) Dentate granule cell layer collagen explant cultures: spontaneous axonal growth and induction by brain-derived neurotrophic factor or basic fibroblast growth factor. Neuroscience 74:1197-1208.

Lowenstein DH, Arsenault L (1996b) The effects of growth factors on the survival and differentiation of cultured dentate gyrus neurons. J Neurosci 16:1759-1769.

Lynch M, Sutula T (2000) Recurrent excitatory connectivity in the dentate gyrus of kindled and kainic acid-treated rats. J Neurophysiol 83:693-704.

Mathern GW, Babb TL, Micevych PE, Blanco CE, Pretorius JK (1997) Granule cell mRNA levels for BDNF, NGF, and NT-3 correlate with neuron losses or supragranular mossy fiber sprouting in the chronically damaged and epileptic human hippocampus. Mol Chem Neuropathol 30:53-76.

Molnar P, Nadler JV (1999) Mossy fiber-granule cell synapses in the normal and epileptic rat dentate gyrus studied with minimal laser photostimulation. J Neurophysiol 82:1883-1894.

Muller D, Djebbara-Hannas Z, Jourdain P, Vutskits L, Durbec P, Rougon G, Kiss JZ (2000) Brain-derived neurotrophic factor restores longterm potentiation in polysialic acid-neural cell adhesion moleculedeficient hippocampus. Proc Natl Acad Sci USA 97:4315-4320.

Murray KD, Isackson PJ, Eskin TA, King MA, Montesinos SP, Abraham LA, Roper SN (2000) Altered mRNA expression for brain-derived neurotrophic factor and type II calcium/calmodulin-dependent protein kinase in the hippocampus of patients with intractable temporal lobe epilepsy. J Comp Neurol 418:411-422.

Nadler JV, Perry BW, Cotman CW (1980) Selective reinnervation of hippocampal area CA1 and the fascia dentata after destruction of CA3-CA4 afferents with kainic acid. Brain Res 182:1-9.

Nawa H, Carnahan J, Gall C (1995) BDNF protein measured by a novel enzyme immunoassay in normal brain and after seizure: partial disagreement with mRNA levels. Eur J Neurosci 7:1527-1535.

Okazaki MM, Evenson DA, Nadler JV (1995) Hippocampal mossy fiber sprouting and synapse formation after status epilepticus in rats: visualization after retrograde transport of biocytin. J Comp Neurol $352 \cdot 515-534$.

Okazaki MM, Molnar P, Nadler JV (1999) Recurrent mossy fiber pathway in rat dentate gyrus: synaptic currents evoked in presence and absence of seizure-induced growth. J Neurophysiol 81:1645-1660.

Parent JM, Yu TW, Leibowitz RT, Geschwind DH, Sloviter RS, Lowenstein DH (1997) Dentate granule cell neurogenesis is increased by seizures and contributes to aberrant network reorganization in the adult rat hippocampus. J Neurosci 17:3727-3738.

Parent JM, Tada E, Fike JR, Lowenstein DH (1999) Inhibition of dentate granule cell neurogenesis with brain irradiation does not prevent seizure-induced mossy fiber synaptic reorganization in the rat. J Neurosci 19:4508-4519.

Patapoutian A, Reichardt LF (2001) Trk receptors: mediators of neurotrophin action. Curr Opin Neurobiol 11:272-280.

Patel MN, McNamara JO (1995) Selective enhancement of axonal branching of cultured dentate gyrus neurons by neurotrophic factors. Neuroscience 69:763-770.

Qiao X, Suri C, Knusel B, Noebels JL (2001) Absence of hippocampal mossy fiber sprouting in transgenic mice overexpressing brain-derived neurotrophic factor. J Neurosci Res 64:268-276.

Ramon y Cajal S (1893) The structure of Ammon's horn. Anal Soc Esp Histol Nat 22.

Represa A, Ben-Ari Y (1992) Kindling is associated with the formation of novel mossy fibre synapses in the CA3 region. Exp Brain Res 92:69-78.

Ribak CE, Tran PH, Spigelman I, Okazaki MM, Nadler JV (2000) Status epilepticus-induced hilar basal dendrites on rodent granule cells contribute to recurrent excitatory circuitry. J Comp Neurol 428:240-253.

Rudge JS, Mather PE, Pasnikowski EM, Cai N, Corcoran T, Acheson A, Anderson K, Lindsay RM, Wiegand SJ (1998) Endogenous BDNF protein is increased in adult rat hippocampus after a kainic acidinduced excitotoxic insult, but exogenous BDNF is not neuroprotective. Exp Neurol 149:398-410.

Scharfman HE, Goodman JH, Sollas AL (2000) Granule-like neurons at the hilar/CA3 border after status epilepticus and their synchrony with area CA3 pyramidal cells: functional implications of seizure-induced neurogenesis. J Neurosci 20:6144-6158.

Scharfman HE, Goodman JH, Sollas AL, Croll SD (2002) Spontaneous limbic seizures after intrahippocampal infusion of brain-derived neurotrophic factor. Exp Neurol 174:201-214.

Seki T, Arai Y (1991) The persistent expression of a highly polysialylated NCAM in the dentate gyrus of the adult rat. Neurosci Res 12:503-513.

Seki T, Arai Y (1999) Temporal and spatial relationships between PSANCAM-expressing, newly generated granule cells and radial glia-like cells in the adult dentate gyrus. J Comp Neurol 410:503-513.

Seress L, Pokorny J (1981) Structure of the granular layer of the rat dentate gyrus. A light microscopic and Golgi study. J Anat 133:181-195.

Seress L, Ribak CE (1990) Postnatal development of the light and electron microscopic features of basket cells in the hippocampal dentate gyrus of the rat. Anat Embryol (Berl) 181:547-565.

Sholl D (1953) Dendritic organization in the neurons of the visual and motor cortices of the cat. J Anat 87:387-406.

Smith MA, Zhang LX, Lyons WE, Mamounas LA (1997) Anterograde transport of endogenous brain-derived neurotrophic factor in hippocampal mossy fibers. NeuroReport 8:1829-1834.

Spigelman I, Yan XX, Obenaus A, Lee EY, Wasterlain CG, Ribak CE (1998) Dentate granule cells form novel basal dendrites in a rat model of temporal lobe epilepsy. Neuroscience 86:109-120.

Stoppini L, Buchs PA, Muller D (1991) A simple method for organotypic cultures of nervous tissue. J Neurosci Methods 37:173-182.

Sutula T, He XX, Cavazos J, Scott G (1988) Synaptic reorganization in the hippocampus induced by abnormal functional activity. Science 239:1147-1150.

Sutula T, Cascino G, Cavazos J, Parada I, Ramirez L (1989) Mossy fiber synaptic reorganization in the epileptic human temporal lobe. Ann Neurol 26:321-330.

Takahashi M, Hayashi S, Kakita A, Wakabayashi K, Fukuda M, Kameyama S, Tanaka R, Takahashi H, Nawa H (1999) Patients with temporal lobe epilepsy show an increase in brain-derived neurotrophic factor protein and its correlation with neuropeptide Y. Brain Res 818:579-582.

Tauck DL, Nadler JV (1985) Evidence of functional mossy fiber sprouting in hippocampal formation of kainic acid-treated rats. J Neurosci 5:1016-1022.

Vezzani A, Ravizza T, Moneta D, Conti M, Borroni A, Rizzi M, Samanin R, Maj R (1999) Brain-derived neurotrophic factor immunoreactivity in the limbic system of rats after acute seizures and during spontaneous 
convulsions: temporal evolution of changes as compared to neuropeptide Y. Neuroscience 90:1445-1461.

Vutskits L, Djebbara-Hannas Z, Zhang H, Paccaud JP, Durbec P, Rougon G, Muller D, Kiss JZ (2001) PSA-NCAM modulates BDNF-dependent survival and differentiation of cortical neurons. Eur J Neurosci 13: 1391-1402.

Wenzel HJ, Woolley CS, Robbins CA, Schwartzkroin PA (2000) Kainic acid-induced mossy fiber sprouting and synapse formation in the dentate gyrus of rats. Hippocampus 10:244-260.

Wetmore C, Olson L, Bean AJ (1994) Regulation of brain-derived neurotrophic factor (BDNF) expression and release from hippocampal neurons is mediated by non-NMDA type glutamate receptors. J Neurosci 14:1688-1700.

Wuarin JP, Dudek FE (1996) Electrographic seizures and new recurrent excitatory circuits in the dentate gyrus of hippocampal slices from kainate-treated epileptic rats. J Neurosci 16:4438-4448.

Wuarin JP, Dudek FE (2001) Excitatory synaptic input to granule cells increases with time after kainate treatment. J Neurophysiol 85: 1067-1077.

Yacoubian TA, Lo DC (2000) Truncated and full-length TrkB receptors regulate distinct modes of dendritic growth. Nat Neurosci 3:342-349.

Yan Q, Rosenfeld RD, Matheson CR, Hawkins N, Lopez OT, Bennett L, Welcher AA (1997) Expression of brain-derived neurotrophic factor protein in the adult rat central nervous system. Neuroscience 78: 431-448.

Zafirov S, Heimrich B, Frotscher M (1994) Dendritic development of dentate granule cells in the absence of their specific extrinsic afferents. J Comp Neurol 345:472-480. 